\title{
Evaluation of Steel Stairwell Dynamic Characteristics, Under Few Mass Configurations Using Ambient Vibration Method
}

\author{
Ahmad Fahmy Kamarudin 1,*, Shahrul Niza Mokhatar, Mohammad Soffi Md \\ Noh $^{1}$, Mohammad Azim Mohd Sulaiman ${ }^{2}$, Amira Nurhayati Abdul Haris ${ }^{2}$, \\ Mohd Hazreek Zainal Abidin ${ }^{2}$, Mohd Effendi Daud², Azmi Ibrahim ${ }^{3}$ and \\ Zainah Ibrahim ${ }^{4}$
}

${ }^{1}$ Jamilus Research Center,

Universiti Tun Hussein Onn Malaysia, 86400 Parit Raja, Johor, MALAYSIA

${ }^{2}$ Faculty of Civil and Environmental Engineering,

Universiti Tun Hussein Onn Malaysia, 86400 Parit Raja, Johor, MALAYSIA

${ }^{3}$ Faculty of Civil Engineering,

Universiti Teknologi MARA, 40450 Shah Alam, Selangor, MALAYSIA

${ }^{4}$ Department of Civil Engineering,

Faculty of Engineering, Universiti Malaya, 50600 Kuala Lumpur, MALAYSIA

*Corresponding Author

DOI: https://doi.org/10.30880/ijie.2019.11.06.024

Received 13 January 2019; Accepted 12 June 2000; Available online 01 September 2019

\begin{abstract}
Application of external mass on existing emergency steel stairwell in this study has altered the natural frequency when the resonance threshold has been reached and allows disruption to the human comfort feeling. Ambient vibration testing and modal analysis were carried out on 6 meter height of emergency steel stairway portal frame by using $1 \mathrm{~Hz}$ of tri-axial seismometer sensor and open source software of GEOPSY as the processing tool. The stairwell platforms were subjected by cumulative ascending static mass configurations of $300 \mathrm{~kg}, 600 \mathrm{~kg}$ and $900 \mathrm{~kg}$. Identification of the predominant first mode frequency, f1, and mode shapes were made with specified empirical filtering protocols were applied. Fourier Amplitude Spectra (FAS) was used to transform the ambient vibration time series, when the first predominant frequency under bare frame (BF) condition shows at $8.32 \mathrm{~Hz}$. f1 decreased linearly to $7.35 \mathrm{~Hz}(\mathrm{BF}+300 \mathrm{~kg}), 6.77 \mathrm{~Hz}(\mathrm{BF}+600 \mathrm{~kg})$ and $6.23 \mathrm{~Hz}(\mathrm{BF}+900 \mathrm{~kg})$, when the masses were increased. In addition, at these frequencies' ranges, bad human subjective experiences could be triggered as recommended by previous researchers between 8 to $5 \mathrm{~Hz}$. Besides, the deflection shapes from the first mode frequency was also illustrated at higher deflection amplitude to one of the portal frame's column which resisting two stairwell platforms. These amplitudes are higher when f1 is decreasing. It can be concluded that, ambient vibration approach has efficiently evaluated the dynamic characteristics and its influence against the structureperson interaction on existing steel stairwell portal frame in this study. Further strengthening work on the steel frame could decrease the reductions percentages of the predominant frequencies, deflection amplitudes and even increase the human comfort level when using the stairwell, especially during building evacuation procedure.
\end{abstract}

Keywords: Ambient vibration, dynamic characteristics, resonance, natural frequency and mode shapes 


\section{Introduction}

Fire exit is an alternatives and faster route that must be accessible, strategic and safe against evacuees to abandon building and saving lives who are under emergency situations such as fire, earthquake, hazardous materials leakage etc. For a multistorey building, the common practice of steel stairwell is exteriorly built and attached to the main existing structure to allow for emergency evacuation from upper floors to ground. However, most of these emergency stairwells are designed to accommodate dead and imposed loads without consideration of vibration effects.

During emergency evacuation, a steel stairwell will be subjected to uncertain human masses that could trigger disconformity and fear of structural collapse due excessive vibrations and triggering the effect between person to structure interactions. When the natural frequency of the stairwell coincides with, or closer to the forcing frequency which excited by human rhythmic activities such as running, walking or jumping, resonance could be occurred. The influence of this vibration effects can be simply identified through their dynamic characteristics or modal parameters such as natural period (inversely to natural frequency), mode shape and damping ratio.

According to [1], investigation on structural dynamic characteristics may allow in diagnosing noise and vibration, evaluating the influence of loading or operational conditions, the effects perturbation in structure properties, which assist in controlling and optimizing the behavior of structure. Human masses could act as variable load on building and manipulates the structural response of their dynamic characteristics. Human activities on structure often lead to the excessive vibration and disturbance, especially when there has the phenomenon of resonance [2].

Application of natural frequency as diagnostic parameter has its basis on the assumption that this parameter has sensitive indicator against structural integrity [3]. Ambient vibration testing (AVT) is popularly used nowadays especially in determination of ground or structures natural frequency due to quick data collection and analysis, fewer operators required, non-destructive and without requiring sufficient existing record of as-built design. In current trend of construction technologies and innovation, renewable materials, lightweight, rapid constructions techniques etc. are emphasized [4]-[7] and further investigation on their dynamic behaviour should not be left behind.

From the ambient vibration testing the linearity and nonlinearity behavior of the structure can be explained through small amplitude of vibration that called as microtremor such as in detection of structural stiffness degradation or alteration via its dynamic behavior. According to [8], this microtremor source can provide useful information within short period of recording in the areas of low or even no seismicity, such as dynamic characteristics of ground, structures and effect on surface geology. In fact, it has also been expanded in estimating vulnerabilities of all types of structures and ground. Ambient vibration test has also been used to identify the dynamic characteristics of ground and different types of building [9,10,11], that very useful in resonance effect studies [12],[13]. According to [14], through the study on building diagnosis, it shows that in structural damage detection, the natural frequency is not the only one to be considered as the main parameter but also important to their mode shape evaluation.

Based on previous researches [3],[12],[15], the vibration-based damage identification and structural mass-stiffness modifications could be evaluated through the variation or changes in dynamic characteristics. It is evident that damage can be identified by examining the variation of natural frequencies and mode shape, but damage-induced frequency changes are relatively small but in contrast to mode shapes when their derivatives with local information are more sensitive to local damage or multiple damage detection [16]. Even though there have many opinions and recommendations in evaluating the effectiveness of natural frequencies and mode shapes as a part of measuring tool in modifying the dynamic characteristics of a structure, the influence of excessive mass could be associated to vulnerable on vibration effect especially to emergency stairwell, which must not be neglected. More attention and extra work must be put into further investigation on their characteristics, which consequently effecting to resonance effect that influenced by person-structure interaction. Therefore, in this study, a series of ambient vibration testing were performed on two storey steel stairwell in Universiti Tun Hussein Onn (UTHM), in order to investigate for any modification on the first mode frequency, $f_{l}$, and its mode shapes under a few mass configurations by using ambient vibration (AV) method.

\section{Methodology}

In general, the methodology of this study is divided into three phases. In the initial phase; observation, site survey and desk study were conducted. Sensors positions, obstruction and potential noise perturbation at study area were identified. In the following phases, AVT was carried out by using $1 \mathrm{~Hz}$ tri-axial seismometer. All sensors were placed on the portal frame of steel stairwell (under bare frame and loaded mass conditions), adjacent structure and ground surface for identification of the stairwell's first mode frequency and its mode shapes. A total mass of $300 \mathrm{~kg}$, 600kg and $900 \mathrm{~kg}$ were applied as a variation of static masses combinations. In the final phase, GEOPSY software was used as processing tool to transform the three main components of AV signals (in the North-South, NS, East-West, EW and vertical directions, UD) into FAS (only for structure) and Horizontal to Vertical Spectra Ratio (HVSR) (only for soil). Overlapping protocols between FAS and HVSR curves, and FAS to HVSR ratio were applied in order to distinguish the first mode frequency of the stairwell and other disputation frequencies from ground and adjacent building. 


\subsection{Steel Stairwell and Observation}

The location of this steel stairwell is next to the South Tower of Faculty of Civil and Environmental Engineering (FKAAS) (see Fig. 1) in UTHM. The stairwell is designed for emergency escape which connecting from the South tower and adjacent annex to the ground area. Currently, the path is temporary used as alternative access from parking area to FKAAS building.

Fig. 2 shows a photograph, stairwell dimensions and illustration of sensor positions on the emergency steel stairwell. The stairs and platforms are built on a single bay portal frame which is fixed on the base, but pinned laterally from the platforms' girders to the adjacent walls. The stairwell has three landing area with 1.9 meter width, 2 meters height between platforms, and a total height of 6 meters of portal frame. From observation that has been made, the stairwell is free from any structural deterioration or damages, unless the stairwell is tends to vibrate and create uncomfortable feeling when there has ascending and descending pedestrian on it. In addition, the vibrations effects are stronger when the numbers of pedestrian are increasing.

In AVT, SESAME guideline [17] has recommended several important outlines with regards to reduction of short period disturbance or noise, such as weather conditions, traffic and pedestrian, construction works, vehicles and machinery, that could affect the quality of ambient vibration signal. A strict precaution has been taken, besides carrying out the AVT during weekends in order to minimize the artificial noises activities.

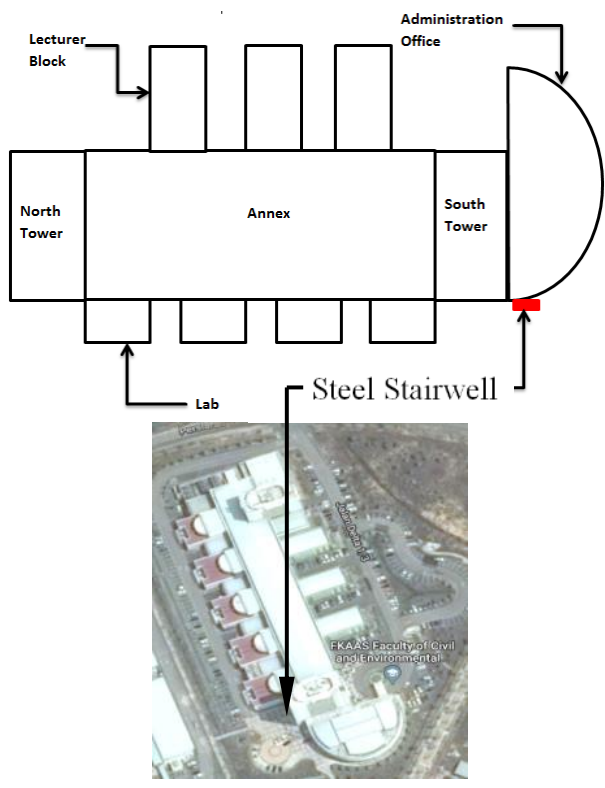

Fig. 1 - Location of steel stairwell and surrounding area.

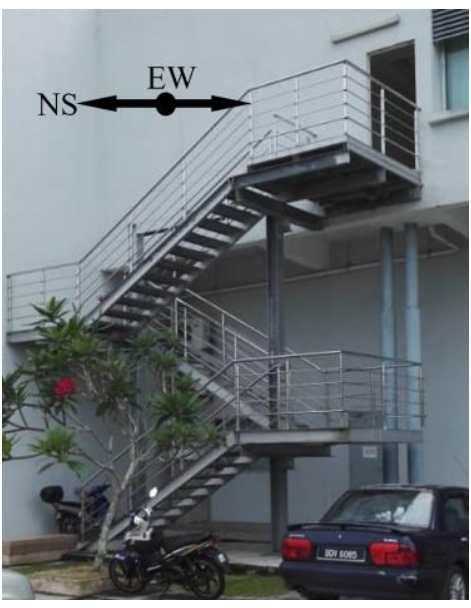

(a)

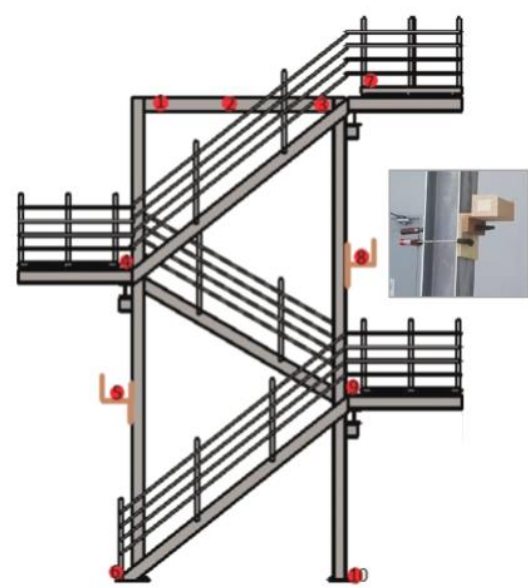

(b)

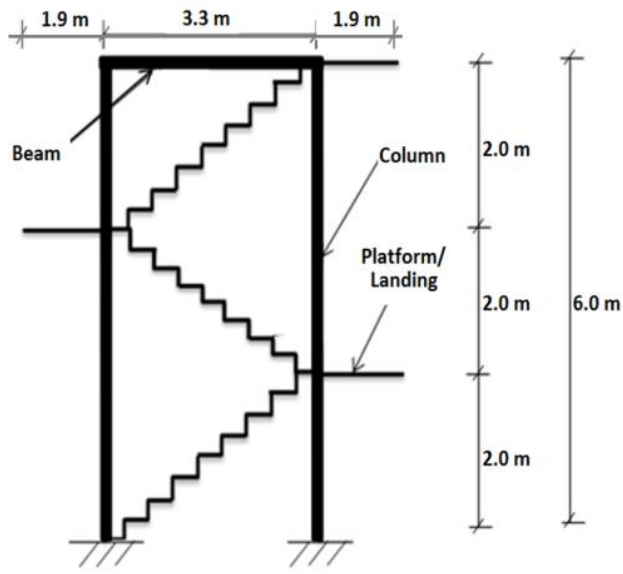

(c)

Fig. 2 - (a) Photographs of the steel stairwell, (b) position of sensor, and (c) dimensions of steel stairwell portal frame. 


\subsection{Ambient Vibration Testing}

Twelve measurement points have been assigned for ambient vibration testing. All seismometers sensor are positioned and attached to the portal frame, except those sensors on the base level, ground and adjacent building ( $1^{\text {st }}$ storey (see Fig. 3(b)). A simple wood bracket has been customized for sensor placement at mid-columns (refer to node 5 and 8) of the portal frame, as illustrated in Fig. 2(b).

For the preparation of mass configurations, 36 unit of $25 \mathrm{~kg}$ sand bags were prepared in this study. This mass was placed on the platform as illustrated in Fig. 3(a), accordingly to the arrangement of total mass sequence of $300 \mathrm{~kg}$, 600 $\mathrm{kg}$ and $900 \mathrm{~kg}$. The sand bags were uniformly distributed on the stairwell platform, in accordance to Table 1 .

Four units of Lennartz triaxial seismometer sensor with $1 \mathrm{~Hz}$ eigenfrequency were connected via four geophone cable to CityShark II data logger with 1 GB of flash card memory. Fig. 4 shows the connection of ambient vibration instruments. The ambient vibration records were taken in three main directions of North-South (NS), East-West (EW) and vertical (UD). All sensors were placed, leveled and aligned to the NS directions as the main reference. Six measurements were conducted and the arrangement of sensor positions for every measurement carried out is tabulated in Table 2.

Ten minutes of recording length was taken for every measurement. A sampling rate of $100 \mathrm{~Hz}$ was used and the gain was optimized but restricted to minimum signal saturation against noise perturbation. It should also be kept in mind that, whatever the type of sensor used, it is not recommended to use too high of a gain, which would result in excessive signal saturation and severely compromise the result [18].

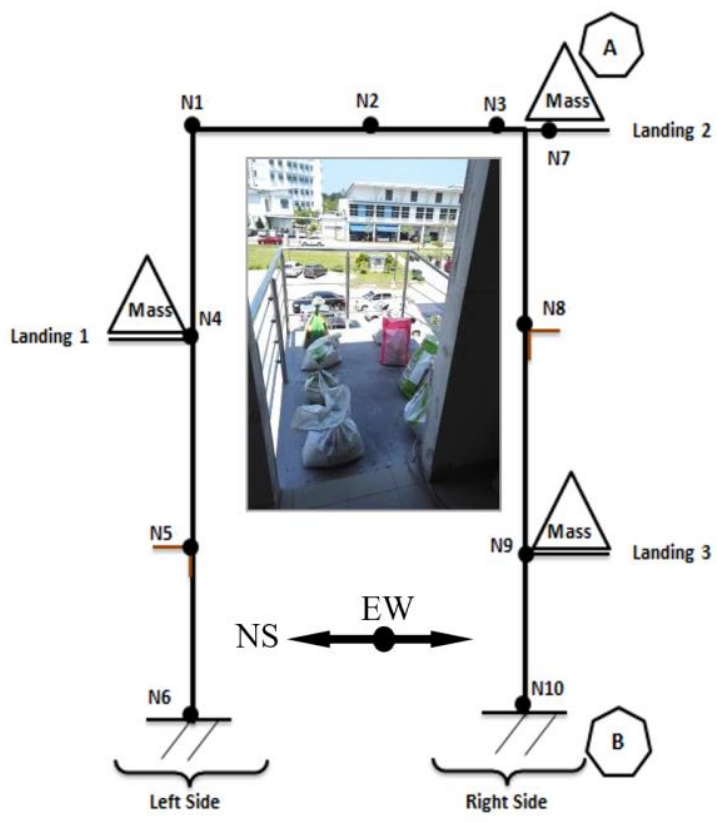

(a)
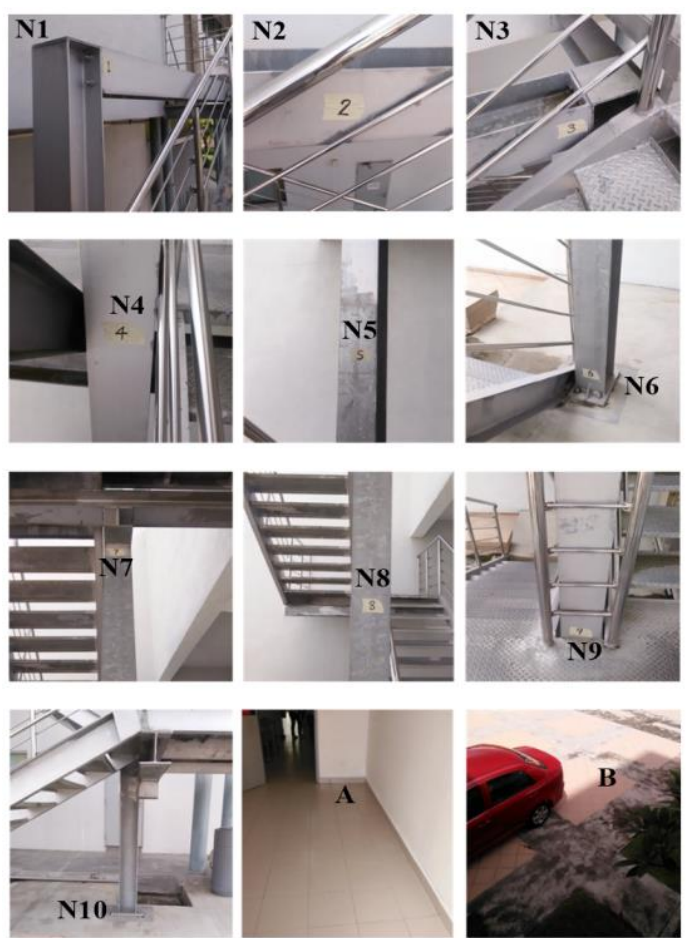

(b)

Fig. 3 - (a) Positions of sensor and mass on the stairwell, and (b) photographs on every measured point.

Table 1 - Mass configurations applied on steel stairwell platforms.

\begin{tabular}{|c|c|c|c|c|}
\hline \multirow{2}{*}{ Round } & $\begin{array}{c}\text { Landing } \\
\text { N4 } \\
(\mathbf{k g})\end{array}$ & $\begin{array}{c}\text { Landing N7 } \\
(\mathbf{k g})\end{array}$ & $\begin{array}{c}\text { Landing N9 } \\
(\mathbf{k g})\end{array}$ & Total Mass (kg) \\
\hline R1 & 100 & 100 & 100 & 300 \\
R2 & 200 & 200 & 200 & 600 \\
\cline { 2 - 5 } R3 & 300 & 300 & 300 & 900 \\
\cline { 2 - 5 } Total Mass per Column & $100^{\mathrm{R} 1} 200^{\mathrm{R} 2} 300^{\mathrm{R} 3}$ & \multicolumn{2}{|c|}{$\begin{array}{c}200^{\mathrm{R} 1} \\
400^{\mathrm{R} 2} \\
600^{\mathrm{R} 3}\end{array}$} \\
\hline
\end{tabular}


Table 2 - Arrangement of ambient vibration measurements on the respective points on the portal frame.

\begin{tabular}{|c|c|c|c|c|}
\hline Measurement No. & $\begin{array}{c}\text { Sensor } \\
\mathbf{1}\end{array}$ & $\begin{array}{c}\text { Sensor } \\
\mathbf{2}\end{array}$ & $\begin{array}{c}\text { Sensor } \\
\mathbf{3}\end{array}$ & $\begin{array}{c}\text { Sensor } \\
\mathbf{4}\end{array}$ \\
\hline M1 & N1 & N2 & N3 & A \\
\hline M2 & N1 & N3 & N7 & N9 \\
\hline M3 & N1 & N8 & N9 & N10 \\
\hline M4 & N1 & N8 & N9 & B \\
\hline M5 & N1 & N2 & N4 & N5 \\
\hline M6 & N1 & N6 & N4 & B5 \\
\hline
\end{tabular}

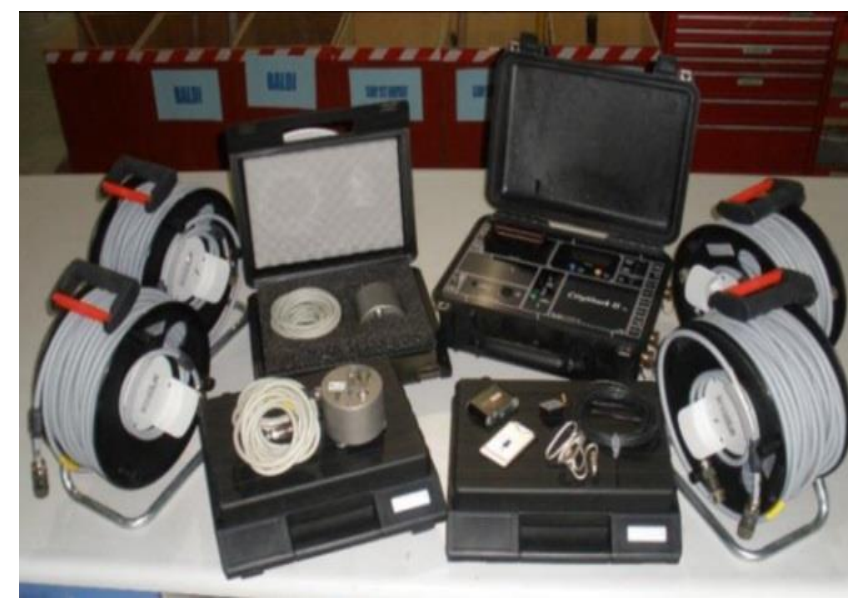

a)

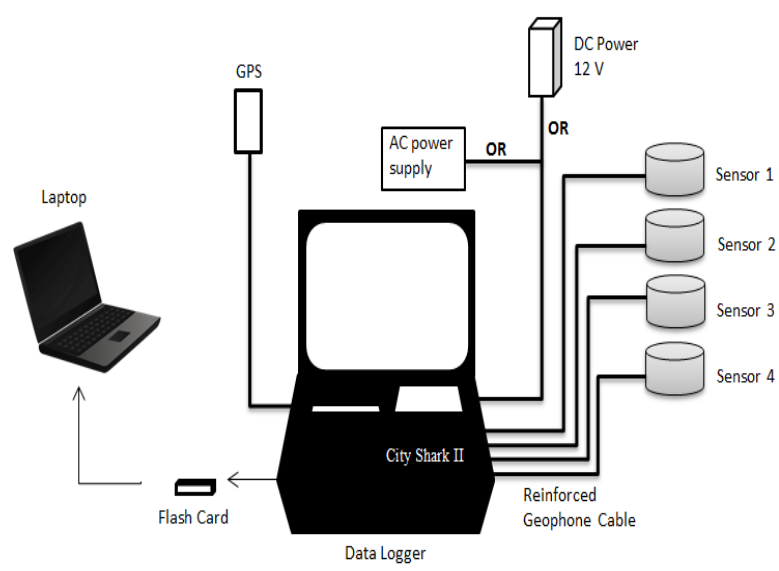

b)

Fig. 4 - (a) Seismometer equipment, and (b) connection of data logger and seismometer sensors.

\subsection{Processing Tools}

All ambient vibration signals in the NS, EW and UD directions were processed using open source software of GEOPSY for identification of the first mode frequency. The conversions of HVSR and FAS from three main components of ambient vibration signals requires several steps, such as signal corrections, signal filtering, computation of Fourier spectral curves, calculations of mean and standard deviation which has been illustrated in Fig. 5. Meanwhile, the standard parameters of ambient vibrations computation procedures recommended by [17], has been applied to the ambient vibration records on ground and building as follows:

i) A standard window selection was split into $10 \mathrm{sec}$ of window length for every time histories components.

ii) Each window was processed using automatic anti-triggering function, to eliminate transients on ground and building measurements (1 sec STA, $30 \mathrm{sec}$ LTA, STA/LTA ratio threshold of 0.20 and 2.50.

iii) A cosine taper $(5 \%)$ has been applied on both sides of each window of all components.

iv) A Konno and Ohmachi smoothing constant was applied at bandwidth of 40.

v) Spectral amplitude through Fast Fourier Transform (FFT) was applied to each window of NS, EW and UD components for the mean FAS outcomes.

vi) Frequency peak picking, using automatic recognition of GEOPSY features which was based on the maximum amplitude of the spectrum.

\subsection{Evaluation of Natural Frequency and Mode Shape}

Initial filtering stage, the peaks frequencies between FAS vs HVSR curves were compared in order to distinguish the origin frequency and amplitudes trends, to enable preliminary evaluation against the natural frequency of steel stairwell and ground. Then, the FAS to HVSR ratio was applied as recommended by [20], in order to verify the dominating frequencies that attribute from steel stairwell portal frame based on a clear peak bump on the spectral ratio.

Evaluation on the first mode frequency of steel stairwell portal frame under bare frame and loaded mass conditions were made in both NS and EW directions, with caution since the dynamic response of the steel stairwell is strongly dominated by adjacent building and soft ground amplifications. Finally, three-dimensional mode shapes illustrations of the steel stairwell portal frame were prepared from respective predominant first mode frequencies obtained. 


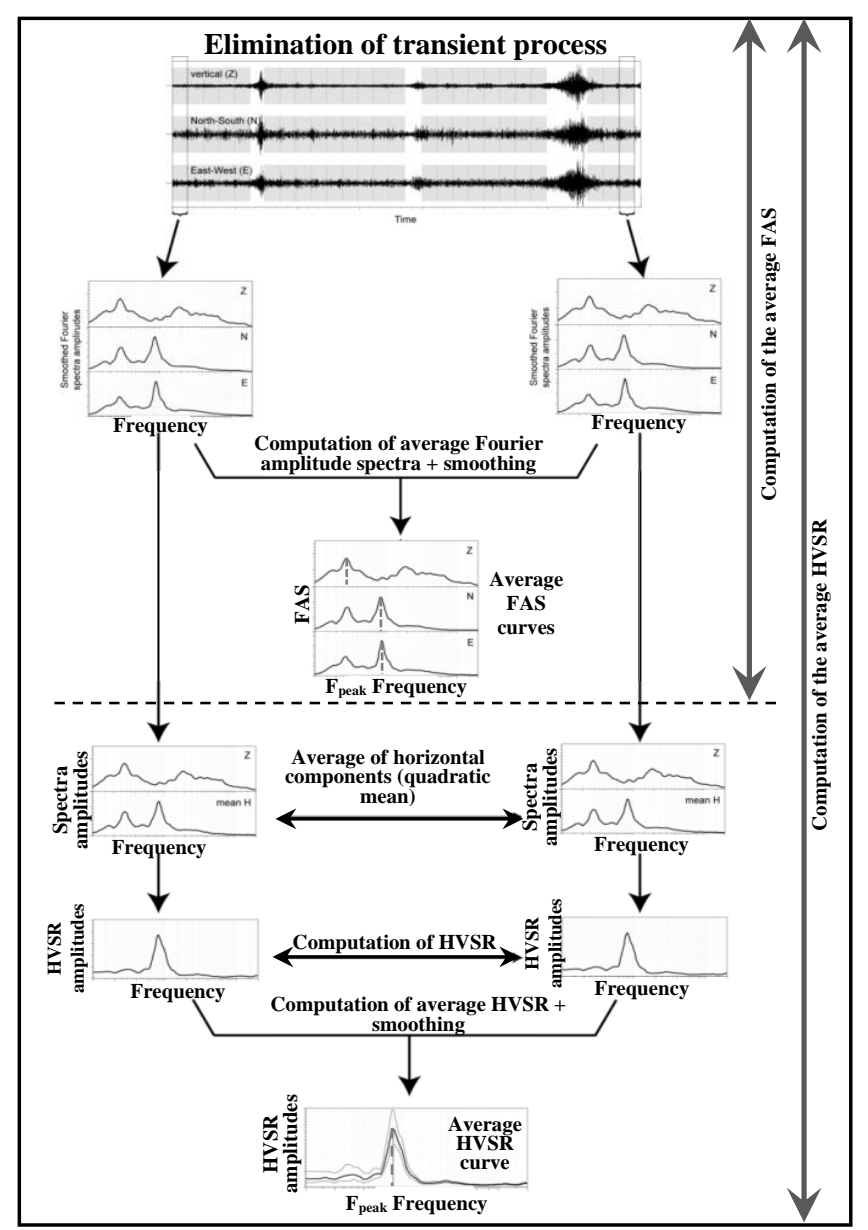

Fig. 5 - Computational procedure of FAS, and HVSR [19].

\section{Results and Discussions}

\subsection{Natural Frequencies}

Humans are particularly sensitive to vibrations with frequencies between 8 to $5 \mathrm{~Hz}$ that corresponding to typical natural frequencies of many main organs in the body [21], [22]. Hence, the vibration signals with higher frequencies can cause a variety of bad human subjective experiences [23]. Due to these main circumstances, the first mode predominant frequency, $\mathrm{f}_{1}$, of the steel stairwell is becoming the main concern in this study against the resonance potential between person-structure interactions.

Few significant peak frequencies were obtained from the NS and EW spectrum curves as shown in Fig. 6 and Fig. 8. The first mode predominant frequency was determined from the maximum peak frequency amplitude of FAS curves based on AV signals recording taken on the upper level of the steel stairwell portal frame (refer to M1 in Table 2). However, care and attention must be emphasized to avoid wrongly choose of this frequency. It is because, the stairwell is pinned laterally to adjacent building, and fixed to a concrete slab at the base which constructed on the soft ground stratification (see Fig. 2(a)). These responses (ground and adjacent building) able to give some frequencies intrusion especially when the dynamic responses and oscillation of ground and adjacent building are more dominant compared to the steel portal frame. From the FAS curves results, it was clearly illustrated by several perturbations peak frequencies observed from the FAS BAREFRAME $_{\text {to }} \mathrm{FAS}_{900 \mathrm{~kg}}$ curves which were attributed by adjacent building and ground at $4.12 \mathrm{~Hz}$ and $1.41 \mathrm{~Hz}$ as given in Fig. 6(a) to (d) and Fig. (a) to (d).

Single peak curves of HVSR spectrum from Fig. 6 to Fig. 9(e) has been indicated to existence of deep contrast soil layer profile underlying the ground surface to the bedrock. Some investigation on similar HVSR trend are also described in [11], [13], [24], [25]. Strong ground amplification could considerably contaminate the structure response and causes misinterpretation of the first mode frequency on building using ambient vibration technique, if without special attention and filtering protocols were taken. Overlapping procedure between HVSR and FAS spectrum has successfully distinguished the existence of ground fundamental frequency at $1.41 \mathrm{~Hz}$ in all FAS curves found from Fig. 6(a) to (d) and Fig. 8(a) to (d). Therefore, at this frequency $(1.41 \mathrm{~Hz})$, it is straightaway neglected from both FAS spectrum of the steel stairwell portal frame in the NS and EW directions. 


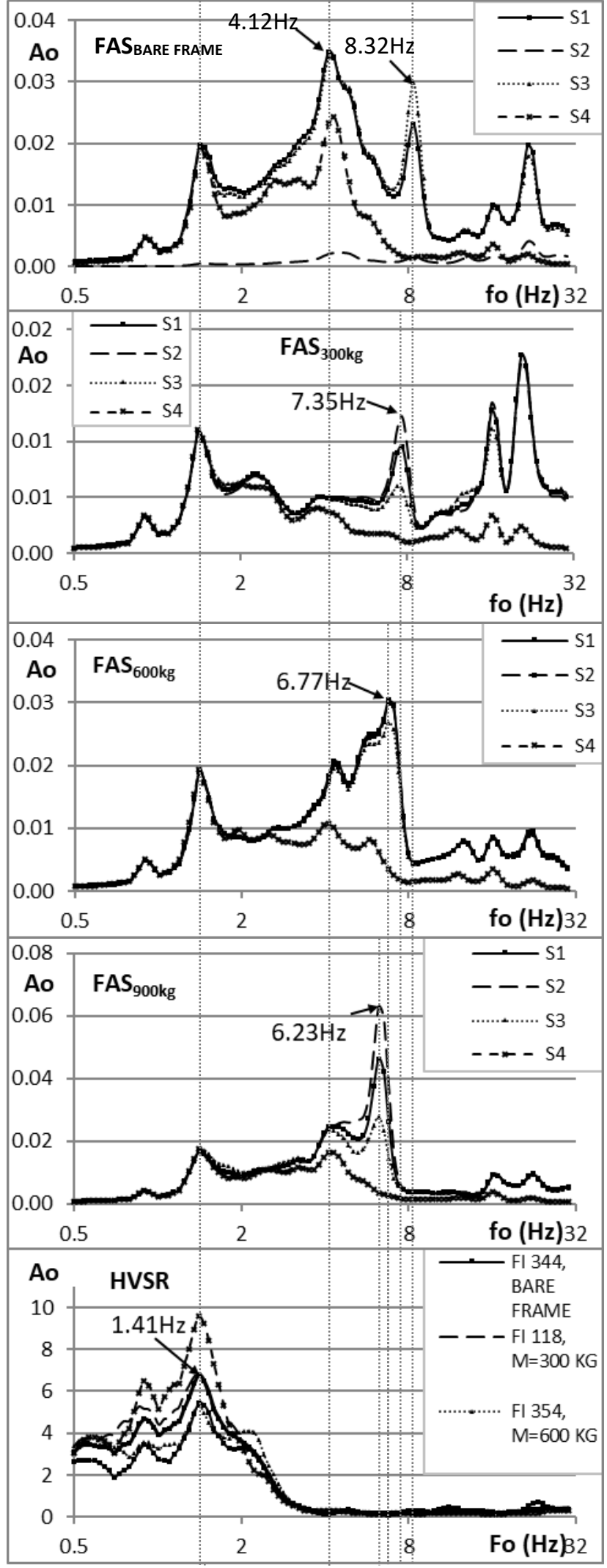

Fig. 6 - FAS curves of steel portal frame from the NS direction on (a) bare frame, (b) bare frame $+300 \mathrm{~kg}$, (c) bare frame $+600 \mathrm{~kg}$, (d) bare frame+900kg and (e) HVSR curves of ground surface.

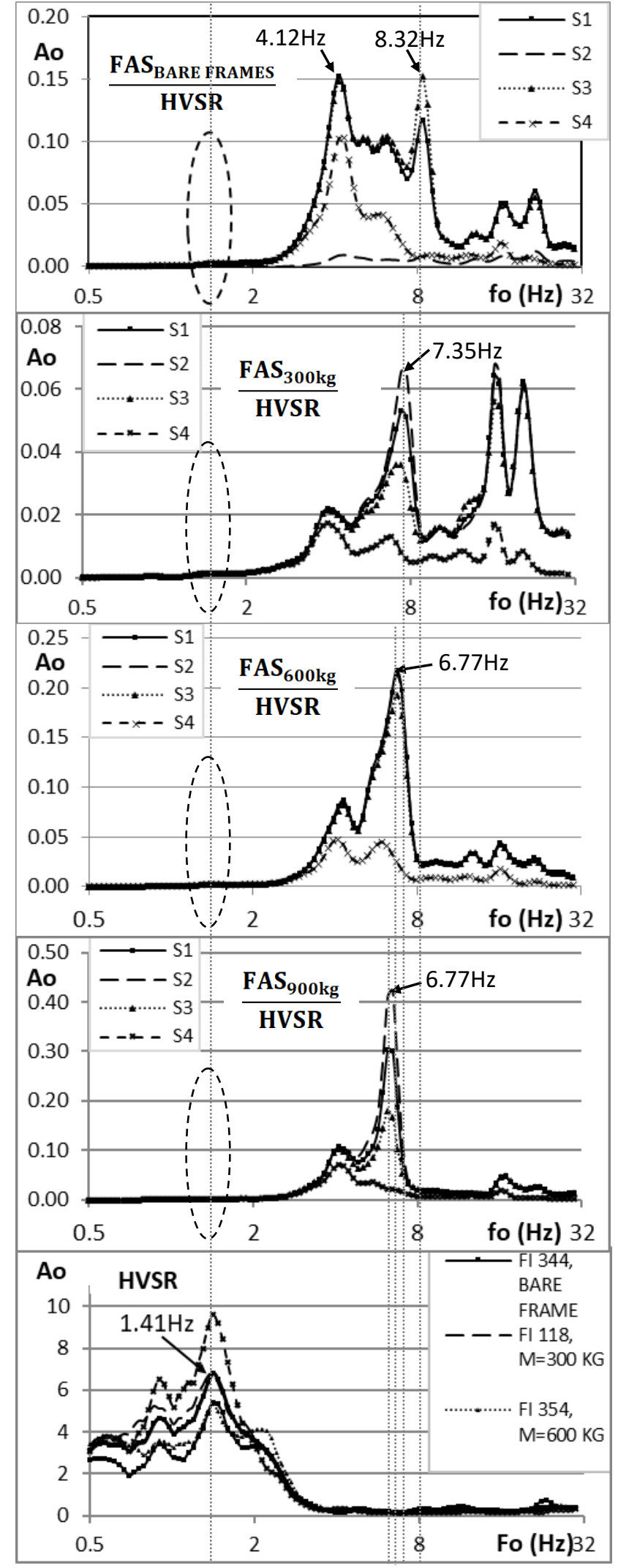

Fig. 7 - FAS to HVSR ration curves of steel portal frame from the NS direction on (a) bare frame, (b) bare frame $+300 \mathrm{~kg}$, (c) bare frame $+600 \mathrm{~kg}$, (d) bare frame+900kg and (e) HVSR curves of ground surface. 


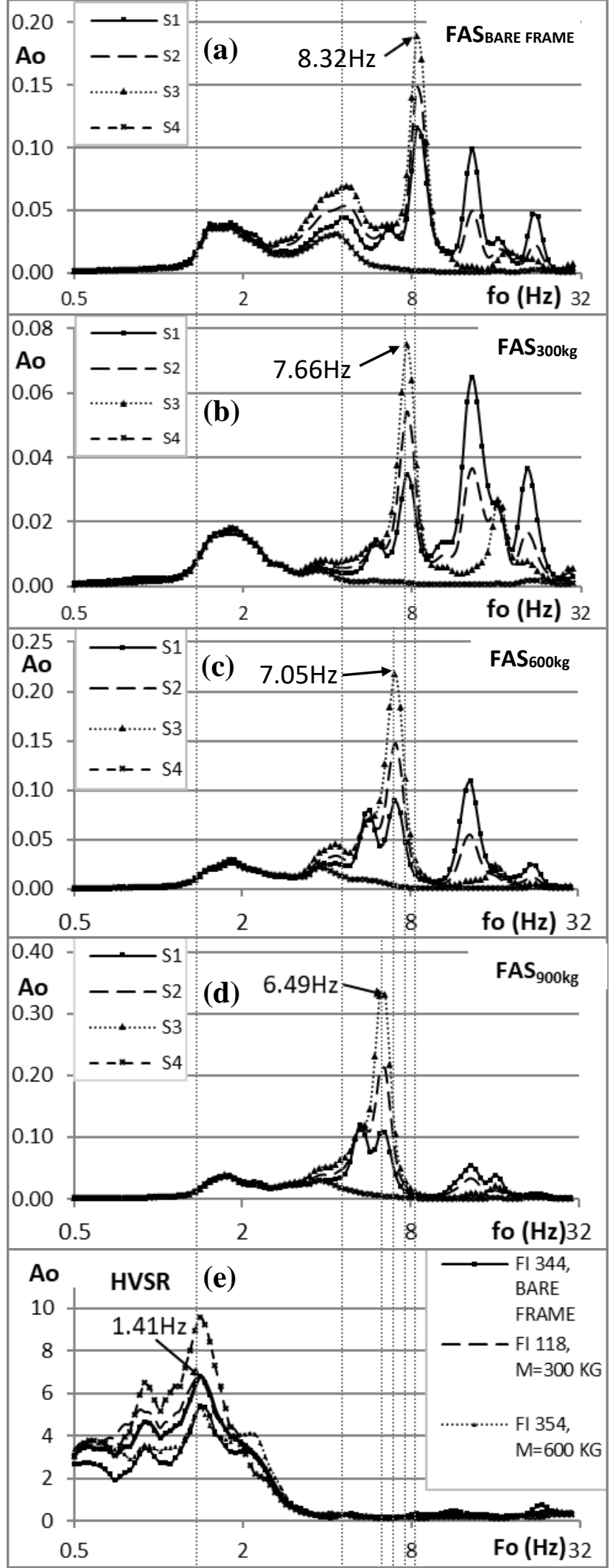

Fig. 8 - FAS curves of steel portal frame from the EW direction on (a) bare frame, (b) bare frame $+300 \mathrm{~kg}$, (c) bare frame $+600 \mathrm{~kg}$, (d) bare frame $+900 \mathrm{~kg}$ and (e) HVSR curves ofground surface.

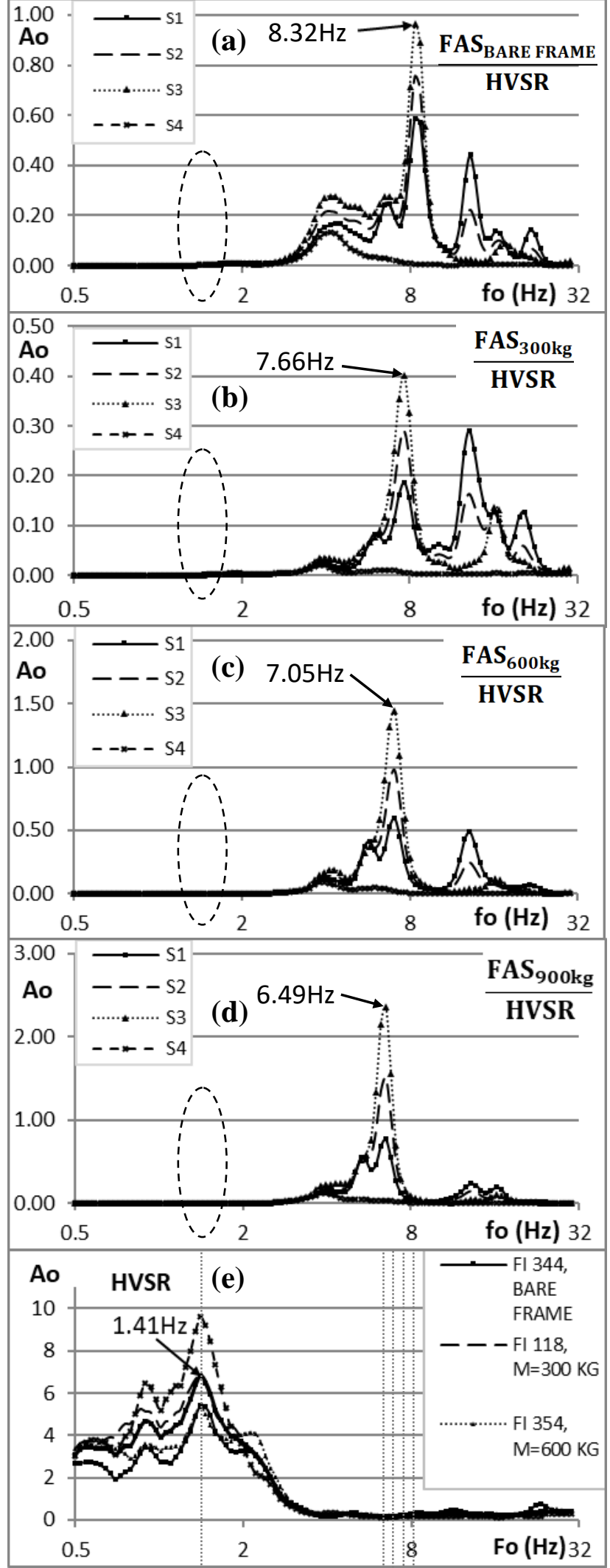

Fig. 9 - FAS to HVSR ration curves of steel portal frame from the $\mathrm{EW}$ direction on (a) bare frame, (b) bare frame $+300 \mathrm{~kg}$, (c) bare frame $+600 \mathrm{~kg}$, (d) bare frame+900kg and (e) HVSR curves of ground surface. 
Again, from the oscillation of adjacent building, it has resulted to the maximum peak frequency at $4.12 \mathrm{~Hz}$ from Fig. 6 (a) that is strongly dominated by FKAAS building, but insignificantly indicated by other FAS curves (see Fig. 6(b) to (d) and Fig. 8 (a) to (d). This amplified frequency needs to be evaluated with caution due to the capability of FAS to HVSR ratio to amplify structural predominant frequencies on both steel stairwell portal frame as well as the adjacent building. But it is successfully showing that, this ratio has able to eliminate the ground natural frequency at $1.41 \mathrm{~Hz}$ (refer Fig. 7 and 9 (a) to (d)).

In order to distinguish the adjacent structure frequency intrusion, it is recommended to conduct ambient vibration recording from adjacent building and the ground surface for their respective natural frequencies. By referring to Table 2, three sensors have been placed on the portal steel frame as given in M1 and M4, however the last sensor was positioned in adjacent building of FKAAS (in M1 measurement) and ground surface (in M4 measurement), as shown in Fig. 3(b).

Six different groups of peak frequencies found in Fig. 6 and 8, at $1.41 \mathrm{~Hz}, 4.12 \mathrm{~Hz}, 6.23$ to $8.32 \mathrm{~Hz}, 13.11$ to $16.13 \mathrm{~Hz}$ and 20.68 to $22.46 \mathrm{~Hz}$ in the NS and EW directions (refer to Table 3 and 4). It is easily identified by S4 from M1 measurement recording, the peak frequencies has initiated at $4.12 \mathrm{~Hz}$ which respectively referred to the adjacent building but none of subsequence peak amplitude is found at higher frequencies (see Fig. 6 and 8, as well as Table 3 and 4). Meanwhile, a single peak of HVSR spectrum curves at $1.41 \mathrm{~Hz}$ of fundamental frequency is initiated by ground response (as given in Fig. 6 to 9 (e)). According to [24] taken from [26], at this range of ground fundamental frequencies (between $1.33 \mathrm{~Hz}$ to $2.00 \mathrm{~Hz}$ ), it can be classified under dense to soft soil classification. Additional frequencies are also predicted at $13.13 \mathrm{~Hz}$ to $16.13 \mathrm{~Hz}$, as well as at several peak curves between 20.68 to $22.46 \mathrm{~Hz}$ from respective FAS curves and FAS to HVSR ratio. However, concern must be emphasized at higher frequencies that could be produced by artificial noises that composed by mechanical equipment from building and construction activities from the nearest construction area.

Table 3: FAS peak frequencies from the NS direction.

\begin{tabular}{|c|c|c|c|c|c|c|}
\hline $\begin{array}{c}\text { Appearance } \\
\text { Ranges }\end{array}$ & Ground & Building & $\begin{array}{l}\text { Bare Frame } \\
\text { (BF) }\end{array}$ & $\begin{array}{c}\text { Bare Frame + } \\
\text { 300kg lump } \\
\text { mass }\end{array}$ & $\begin{array}{c}\text { Bare Frame + } \\
\text { 600kg lump mass }\end{array}$ & $\begin{array}{c}\text { Bare Frame + } \\
\text { 900kg lump mass }\end{array}$ \\
\hline $1.42 \mathrm{~Hz}$ & $\begin{array}{c}1.42 \mathrm{~Hz} \\
(1)(\max )\end{array}$ & $\sqrt{ }$ & $\sqrt{ }$ & $\sqrt{ }$ & $\sqrt{ }$ & $\sqrt{ }$ \\
\hline $\begin{array}{c}4.12 \mathrm{~Hz} \text { to } \\
4.29 \mathrm{~Hz}\end{array}$ & $\sqrt{ }$ & $\begin{array}{c}4.12 \text { to } \\
4.29 \mathrm{~Hz}(1)\end{array}$ & $\sqrt{(\max )}$ & & $\sqrt{ }$ & $\sqrt{ }$ \\
\hline $\begin{array}{c}6.23 \mathrm{~Hz} \text { to } \\
8.32 \mathrm{~Hz}\end{array}$ & & & $8.32 \mathrm{~Hz}(1)$ & $7.35 \mathrm{~Hz}(1)$ & $\begin{array}{l}\text { 6.77 Hz (1) } \\
(\max )\end{array}$ & $\begin{array}{l}6.23 \mathrm{~Hz}(1) \\
(\max )\end{array}$ \\
\hline $16.13 \mathrm{~Hz}$ & & & $\begin{array}{l}16.13 \mathrm{~Hz} \\
\text { (4) }\end{array}$ & $\begin{array}{l}16.13 \mathrm{~Hz} \\
\text { (4) }\end{array}$ & $\begin{array}{c}16.13 \mathrm{~Hz} \\
\text { (4) }\end{array}$ & $\begin{array}{l}16.13 \mathrm{~Hz} \\
\text { (4) }\end{array}$ \\
\hline $\begin{array}{c}20.68 \mathrm{~Hz} \text { to } \\
22.46 \mathrm{~Hz}\end{array}$ & & & $\sqrt{ }$ & $\begin{array}{c}\sqrt{ } \\
(\max )\end{array}$ & $\sqrt{ }$ & $\sqrt{ }$ \\
\hline
\end{tabular}

Table 4: FAS peak frequencies from the EW direction.

\begin{tabular}{|c|c|c|c|c|c|c|}
\hline $\begin{array}{c}\text { Appearance } \\
\text { Ranges }\end{array}$ & Ground & Building & $\begin{array}{c}\text { Bare Frame } \\
\text { (BF) }\end{array}$ & $\begin{array}{c}\text { Bare Frame }+ \\
\text { 300kg lump } \\
\text { mass }\end{array}$ & $\begin{array}{c}\text { Bare Frame + } \\
\text { 600kg lump mass }\end{array}$ & $\begin{array}{c}\text { Bare Frame + } \\
\text { 900kg lump } \\
\text { mass }\end{array}$ \\
\hline $\begin{array}{c}1.42 \mathrm{~Hz} \text { to } \\
1.80 \mathrm{~Hz}\end{array}$ & $\begin{array}{c}1.42 \mathrm{~Hz} \\
(1)(\mathrm{max})\end{array}$ & $\sqrt{ }$ & $\sqrt{ }$ & $\sqrt{ }$ & $\sqrt{ }$ \\
\hline $\begin{array}{c}3.79 \mathrm{~Hz} \text { to } \\
5.98 \mathrm{~Hz}\end{array}$ & $\sqrt{ }$ & $\begin{array}{c}3.79 \mathrm{to} \\
4.29 \mathrm{~Hz}(1)\end{array}$ & $\sqrt{ }$ & & $\sqrt{ }$ & $\sqrt{ }$ \\
\hline $\begin{array}{c}6.49 \mathrm{~Hz} \text { to } \\
8.32 \mathrm{~Hz}\end{array}$ & & & $\begin{array}{c}8.32 \mathrm{~Hz}(1) \\
(\mathrm{max})\end{array}$ & $\begin{array}{c}7.66 \mathrm{~Hz}(2) \\
(\mathrm{max})\end{array}$ & $\begin{array}{c}7.05 \mathrm{~Hz}(2) \\
(\mathrm{max})\end{array}$ & $\begin{array}{c}6.49 \mathrm{~Hz}(2) \\
(\mathrm{max})\end{array}$ \\
\hline $\begin{array}{c}13.11 \mathrm{~Hz} \\
20.68 \mathrm{~Hz} \text { to }\end{array}$ & & & $\begin{array}{c}13.11 \mathrm{~Hz} \\
(3)\end{array}$ & $\begin{array}{c}13.11 \mathrm{~Hz} \\
(3)\end{array}$ & $\begin{array}{c}13.11 \mathrm{~Hz} \\
(3)\end{array}$ & $\begin{array}{c}13.11 \mathrm{~Hz} \\
(3)\end{array}$ \\
\hline $2.46 \mathrm{~Hz}$ & & & $\sqrt{ }$ & $\sqrt{ }$ & $\sqrt{ }$ \\
\hline
\end{tabular}

Increasing static mass on the steel stairwell landing is applied accumulatively from $300 \mathrm{~kg}, 600 \mathrm{~kg}$ to $900 \mathrm{~kg}$, has produced linear decreasing pattern of the first peak frequency in both NS and EW directions as illustrated in Fig. 10. Under the bare frame condition to maximum mass loaded up to $900 \mathrm{~kg}$, the first mode predominant frequencies of the steel stairwell portal frame has reduced from $8.32 \mathrm{~Hz}$ to $6.49 \mathrm{~Hz}$ in the NS direction, and $8.32 \mathrm{~Hz}$ to $6.23 \mathrm{~Hz}$ in the EW 
direction, with approximate $2.09 \mathrm{~Hz}$ to $2.01 \mathrm{~Hz}$ of loses or equivalent to more than $23 \%$ of frequency reduction in both directions. By taking the assumption with average normal body weight of a person at $70 \mathrm{~kg}$, the action of 13 people could able to put the natural frequency of the stairwell into bad human subjective experiences circumstance $(8 \mathrm{Ho} 5 \mathrm{~Hz})$ with more than $23 \%$ of frequency reduction. Worst, resonance effect can be induced to uncomfortable feeling to a person under this circumstance, especially during building evacuation procedure.

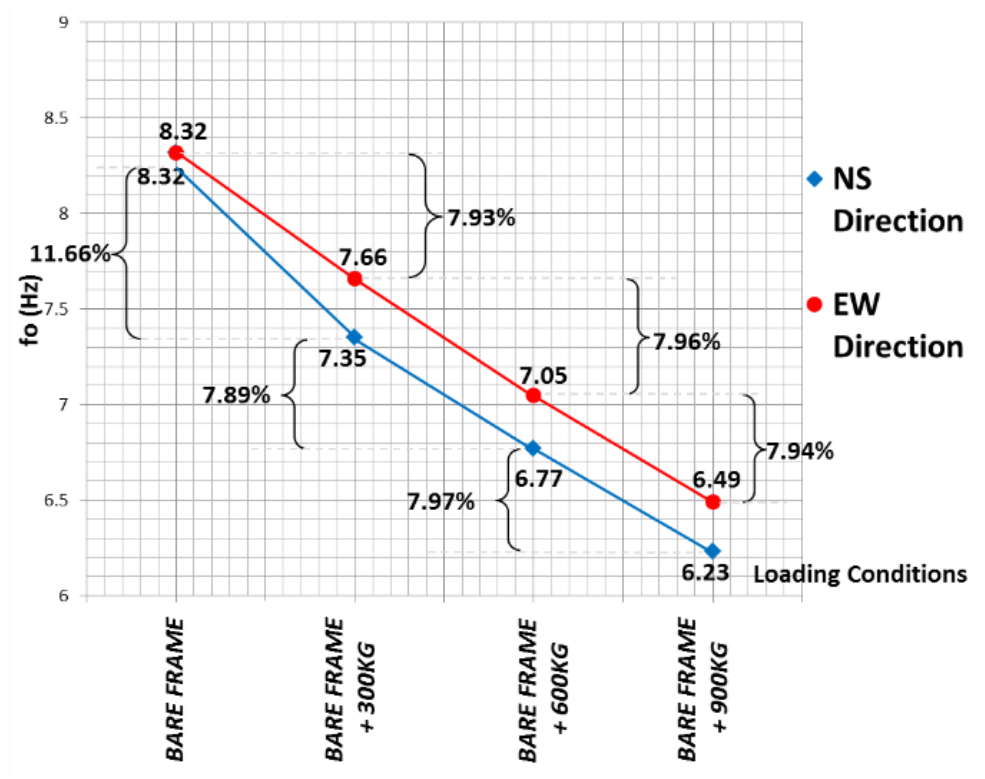

Fig. 10 - Linear decreasing pattern on the first predominant frequencies with increasing mass applied.

\subsection{Mode Shapes}

Fig. 11 shows a series of the mode shape under bare frame and loaded mass conditions. From the peak frequencies of FAS curves as given in Fig. 6 and Fig. 8, the deformation of the stairwell portal frame has been found in translational shape for respective first mode of frequencies. The deflection amplitude has been increased when the frequencies is decreasing (when the mass is ascending). Bigger deflection amplitude was found on the right column of the portal frame, compared to the left column (see Fig. 12(a) to (d)). Higher amplitude was expected on this column due to extra masses applied on both stairwell landing (platform 2 and 3). Meanwhile, the position of platform 1 was supported by the left column and pinned to the adjacent wall has given to additional lateral restrained against lateral movement. Stiffening the portal frame by lateral bracing system or with additional column supports to cantilevered platforms, could rises the first mode frequency and keeping away from the resonance zone under the influence of person-structure interaction. This could increase the sense of safety, avoid fear and undesirable human feeling especially during evacuation procedure.

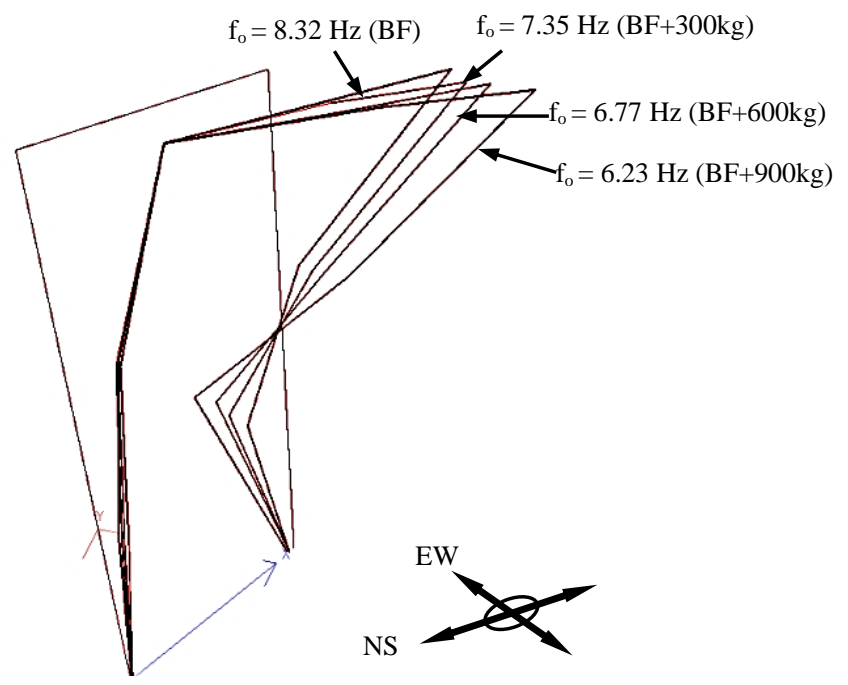

Fig. 11 - Deflection mode shape from respective first mode frequency associated with increasing mass applied. 


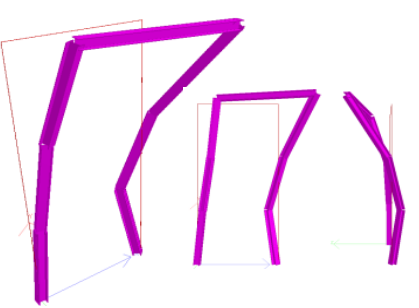

a)

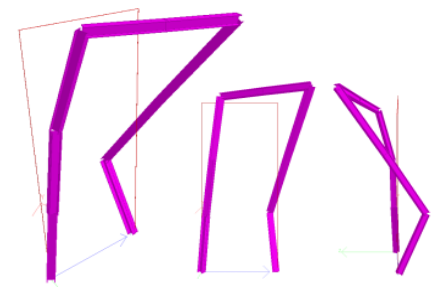

c)

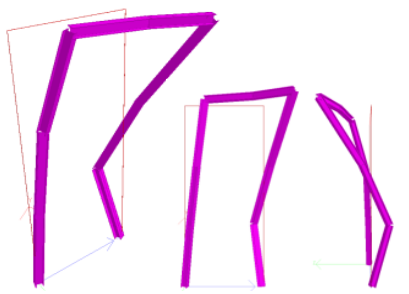

b)

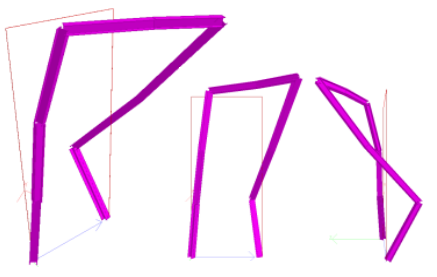

d)

Fig. 12 - Respective first mode of deflection: a) $B F=8.23 \mathrm{~Hz}$, b) $B F+300 \mathrm{~kg}=7.35 \mathrm{~Hz}$, c) $\mathrm{BF}+600 \mathrm{~kg}=6.77 \mathrm{~Hz}$, and d) $\mathrm{BF}+900 \mathrm{~kg}=6.23 \mathrm{~Hz}$.

\section{Conclusion}

It is important to conclude that ambient vibration technique is very efficient to identify the dynamic characteristics of the steel stairwell portal frame for their first mode frequency and its mode shape. The application of ascending mass on the structure has amplified the frequencies amplitudes of the stairwell even though this stairwell is constructed on the soft ground and connected to the adjacent building that could affected to wrongly choose of the right structure frequencies. Finally, extra attention should be given under increasing mass considerations due to the stairwell could be resonated due when the frequencies range reached 8 to $5 \mathrm{~Hz}$, as recommended from previous researchers [21],[22].

\section{Acknowledgement}

The authors would like to acknowledge and expressed gratitude to the financial support by UTHM under TIER 1 Vot. U837, Faculty of Civil and Environmental Engineering UTHM for the instrumentations, as well as to all JRC and RSRS research members for their great cooperation to the accomplishment of this research.

\section{References}

[1] Woon, C.E. and Mitchell, L.D. Variation in structural dynamic charactreistics caused by changes in ambient vibration temperature: I. Experimental. Proceedings of the 14th International Modal Analysis Conference (IMAC XIV). Dearborn, Michigan, USA. February 12-15, (1996), pp. 963-971.

[2] Picauly, F., Priyosulistyo, H., Suhendro, B., and Triwiyono, A. Influence of vibration human activity upon simple supported slab with tuned mass damper (TMD) and fiber reinforced rubber (FRR) absorber. Procedia Engineering, 171, (2017), pp.1186-1193.

[3] Kamarudin, A.F., Mokhatar, S.N., Zainal Abidin, M.H., Daud, M.E., Rosli, M.S., Ibrahim, A., Ibrahim, Z. and Md Noh, M.S. Structural health monitoring on medium rise reinforced concrete building using ambient vibration method. IOP Conf. Series: Earth and Environmental Science Vol. 140 (2018), pp. 1-8.

[4] Md Noh, M.S., Kamarudin, A.F., Mokhatar, S.N., Jaudin, A.R., Ahmad, Z., Ibrahim, A. and Muhammad, A.A. Axial compression behaviour of reinforced wallettes fabricated using wood-wool cement panel. IOP Conference Series: Earth and Environmental Science Volume 140, Issue 1, (2018), pp. 1-8.

[5] Md Noh, M.S., Ahmad, Z., Ibrahim, A., Kamarudin, A.F. and Mokhatar, S.N. Static in-plane shear behaviour of prefabricated wood-wool panel wallettes. Journal of Physics: Conference Series Volume 995, Issue 1, (2018), pp. $1-8$.

[6] Jaini, Z. M., Boon, K.H., Mokhatar, S.N., Mat, I., Hazmi, H. and Hashim, N.H. Structural behavior of short-span reinforced concrete beams with foamed concrete infill. ARPN Journal of Engineering and Applied SciencesOpen Access 11, (2016), pp. 9820-9825.

[7] Abdullah, S.R., Riwayat, A.I., Abdul Awal, A.S.M., and Zakaria Hossain, M. Effect of rubber powder particle on the strength of foamed concrete. International Journal of GEOMATE Volume 13, Issue 38, (2017), pp 129-134.

[8] Nakamura, Y. Clear identification of fundamental idea of Nakamura's technique and its applications. 12th World Conference on Earthquake Engineering; Auckland, New Zealand, Sunday 30 Jan-4 Feb, (2000). 
[9] Hamamoto, T. and Ozeki, Y., Seismic vulnerability assessment of reinforce concrete building using microtremor measurements. 12th World Conference on Earthquake Engineering; Auckland, New Zealand, Sunday 30 Jan- 4 Feb, (2000).

[10] Noor, M.A.M., Madun, A., Kamarudin, A.F. and Daud, M.E. A Study of Geological Formation on Different Sites in Batu Pahat, Malaysia Based on HVSR Method Using Microtremor Measurement. IOP Conference Series: Materials Science and Engineering Volume 136, Issue 1, (2016), pp. 1-6.

[11] Kamarudin, A.F. Zainal Abidin, M.H., Mokhatar, S.N., Daud, M.E., Ibrahim, A., Ibrahim, Z. and Md Noh, M.S. Identification of Natural Frequency of Low Rise Building on Soft Ground Profile using Ambient Vibration Method. Journal of Physics: Conference Series Volume 995, Issue 1, (2018). pp. 1-9.

[12] Gallipoli, M.R., Mucciarelli, M., Castro, R.R., Monachesi, G. and Contri, P. Structure, soil-structure response and effects of damage based on observations of horizontal-to-vertical spectral ratios of microtremors, Soil Dynamics and Earthquake Engineering 24, (2004), pp. 487-495.

[13] Gosar, A. Microtremor soil-structure resonance in the Bovec Basin (NW Slovenia) related to 1998 and 2004 damaging earthquake, In Mucciarelli, M., Herak, M. and Cassidy, J., Increasing Seismic Safety by Combining Engineering Technologies and Seismological Data, Netherlands: Springer, (2009), pp. 241-279.

[14] Farsi, M.N., Guillier, B., Chatelain, J.L. and Zermout, S.A. Retrofitting and strengthening evaluation from stiffness variations of a damaged building from ambient vibration recordings. In Mucciarelli, M., Herak, M., and Cassidy, J. Increasing Seismic Safety by Combining Engineering Technologies and Seismological Data, Netherlands: Springer, (2009), pp. 227-238.

[15] Kamarudin, A.F., Zainal Abidin, M.H., Daud, M.E., Noh, M.S., Madun, A., Ibrahim, A., Matarul, J., and Mokhatar, S.N. Natural Frequencies Evaluation on Partially Damaged Building using Ambient Vibration Technique. IOP Conf. Series: Journal of Physics: Conf. Series 99, (2018), pp. 1-8.

[16] Li, Q. and Li, D. Structure damage identification under ambient excitation based on wavelet packet analysis. Journal of Physics: Conf. Series 842, (2017), pp. 1-12.

[17] SESAME, Guidelines for the implementation of the $\mathrm{H} / \mathrm{V}$ spectral ratio technique on ambient vibrations: measurements, processing and interpretation, European Commission - Research General Directorate Project No: EVG1-CT-2000-00026, (2004).

[18] Chatelain, J.L. and Guillier, B. Reliable fundamental frequencies of soils and building down to $0.1 \mathrm{~Hz}$ obtained from ambient vibration recordings with a $4.5 \mathrm{~Hz}$ sensor. Seismological Research Letter 84 (2), (2013), pp 199209.

[19] GEOPSY, H/V measurements. Retrieved on October 14, 2018 from http://www.geopsy.org/ documentation/geopsy/hv.html.

[20] Kamarudin, A.F., Daud, M.E., Ibrahim, A. and Ibrahim, Z. Empirical filtering method for natural frequencies evaluation of low rise reinforced concrete school building using ambient vibration approach. In Kim, D-K., Jung, J, Seo, J. Advances in Civil, Architectural, Structural and Constructional Engineering, Netherlands: CRC Press, Taylor \& Francis Group, (2016), pp. 247-252.

[21] Griffin, M.J. Handbook of Human Vibrations, Elsevier Press, London, England, (1990).

[22] Murray, T.M. Building Floor Vibrations. AISC Engineering Journal, 28(3), (1991), pp. 102-109.

[23] Yao, Q., Yang, X. and Li, H. Development of absorbed blasting vibration energy index for the evaluation of human comfort in multistorey building. Shock and Vibration Vol. (2017), pp 1-12.

[24] Kamarudin, A.F., Md Noh, M.S., Mohd Anuar, M.A., Ibrahim, A., Ibrahim, Z., and Daud, M.E. Influence of traffic vehicles against ground fundamental frequency prediction using ambient vibration technique. IOP Conf. Series: Journal of Physics: Conf. Series Vol. 995, (2018), pp. 1-10.

[25] Kamarudin, A.F., Daud, M.E., Ibrahim, Z., Ibrahim, A. Yub, M.K. and Mohd Noor, M.A., Estimation of Site Dynamic Characteristics from Ambient Noise Measurements using HVSR Method in Microzonation Study: Senggarang, Batu Pahat, Malaysia, Advanced Materials Research, Vols 931-932, (2014), pp. 803-807.

[26] Shinoda, M., Watanabe, K., Kojima, K. and Tateyama, M. Outline of performance-based design for railway earth structure in Japan. In Kokusho, T., Tsukamoto, Y. and Yoshimine, M. Performance-Based Design in Earthquake Geotechnical Engineering-from Case History to Practice, Netherlands CRC Press, (2009), pp. 137-148. 